\title{
Cardiovagal Tone: A Predictor of Heart Rate Adjusted Augmentation Index in Men but Not in Women
}

\author{
Peter L. Latchman'1, Robert Thiel'1, Gregory Gates ${ }^{2}$, Weili Zhu ${ }^{3}$, Robert Axtell' ${ }^{1}$, Kenneth Gardner ${ }^{4}$, \\ William Lunn', Ronald DeMeersman ${ }^{5}$
}

\author{
${ }^{1}$ Exercise Science Department, Southern Connecticut State University, New Haven, CT, USA \\ ${ }^{2}$ Albert Einstein College of Medicine, Yeshiva University, Bronx, NY, USA \\ ${ }^{3}$ Capital University of Physical Education and Sports, Beijing, China \\ ${ }^{4}$ G.C. Foster College of Physical Education and Sports, Spanish Town, Jamaica \\ ${ }^{5}$ Alfaisal University, College of Medicine, Riyadh, KSA \\ Email: Latchmanp1@southernct.edu,rpthiel@thielstatcon.com, ggates@montefiore.org,weili_zhu@163.com, \\ axtellr1@southernct.edu,kwarrengadner@yahoo.com,lunnw1@southernct.edu,rmeersman@alfaisal.edu
}

How to cite this paper: Latchman, P.L., Thiel, R., Gates, G., Zhu, W.L., Axtell, R., Gardner, K., Lunn, W. and DeMeersman, R. (2017) Cardiovagal Tone: A Predictor of Heart Rate Adjusted Augmentation Index in Men but Not in Women. Open Journal of Molecular and Integrative Physiology, 7, 41-51.

https://doi.org/10.4236/ojmip.2017.73004

Received: July 26, 2017

Accepted: August 22, 2017

Published: August 25, 2017

Copyright $\odot 2017$ by authors and Scientific Research Publishing Inc. This work is licensed under the Creative Commons Attribution International License (CC BY 4.0).

http://creativecommons.org/licenses/by/4.0/ (c) (i) Open Access

\begin{abstract}
Purpose: Aortic augmentation index (AIx) and cardiovagal tone (CVT) are indicators of cardiovascular health. Associations between these variables provide information about their roles in cardiovascular disease. However, evaluating these associations from a gender perspective and gaining an understanding of the relationship between cardiorespiratory fitness and AIx based on gender can provide additional information. Therefore, we examined the relationships between CVT, measured as the log transformed high-frequency power of R-R intervals from electrocardiogram measurements $\left(\operatorname{lnHF}_{\mathrm{R}-\mathrm{R}}\right)$; cardiorespiratory fitness, measured as maximum oxygen consumption $\left(\mathrm{VO}_{2} \mathrm{max}\right)$; and AIx at a heart rate of 75 beats.min ${ }^{-1}$ (AIx@75). We hypothesized that the relationships between CVT, cardiorespiratory fitness, and AIx@75 would differ based on gender. Methods: We examined the associations between $\ln \mathrm{HF}_{\mathrm{R}-\mathrm{R}}$, $\mathrm{VO}_{2}$ max, and AIx@75 in 41 women and 39 men. Power spectral density analysis of heart rate variability determined $l \mathrm{nHF}_{\mathrm{R}-\mathrm{R}}$, radial tonometry determined AIx@75 and the Bruce Treadmill Protocol determined $\mathrm{VO}_{2}$ max. Results: In men, $\operatorname{lnHF}_{\mathrm{R}-\mathrm{R}}$ positively correlated with and significantly predicted AIx@75 ( $F$ $=0.005)$ but not in women $(P=0.49)$. For every unit increase in $\operatorname{lnHF}_{\mathrm{R}-\mathrm{R}}$, there was a 4.6 unit increase in AIx@75 in men versus a 1.0 unit increase in women. There was a significant inverse relationship between $\mathrm{VO}_{2} \max$ and AIx@75, with $\mathrm{VO}_{2}$ max being a significant predictor of AIx@75 in men $(P=0.01)$. For every unit increase in $\mathrm{VO}_{2} \max$, there was a 0.60 unit decrease in AIx@75 in men versus a 0.2 unit decrease in women. Conclusions: The associations be-
\end{abstract}


tween CVT and AIx@75 and between cardiorespiratory fitness and AIx@75 differ by gender. CVT and cardiorespiratory fitness are significant predictors of AIx@75 in men but not in women.

\section{Keywords}

Augmentation Index, Heart Rate Variability, Cardiorespiratory Fitness, Cardiovascular Disease

\section{Introduction}

Aortic pressure augmentation and cardiovagal tone (CVT) are indicators of cardiovascular health. Aortic pressure augmentation can be expressed as a percentage of pulse pressure [1], referred to as the augmentation index (AIx). When adjusted to a standard heart rate of 75 beats. $\mathrm{min}^{-1}$, AIx is denoted as AIx@75. AIx is used as a measure of arterial stiffness [2] [3]. Arterial stiffness is considered to be a marker of subclinical vascular disease and an independent predictor of coronary heart disease and stroke in apparently healthy individuals [4] and a predictor of mortality in symptomatic individuals [5]. Additionally, AIx values have been found to strongly correlate with the risk of developing coronary artery disease in asymptomatic individuals with no prior history of coronary artery disease [6], and AIx along with augmentation pressure are considered to be strong independent risk markers for premature disease of the coronary arteries [1] and all causes of cardiovascular death [7].

Heart rate variability (HRV) as a measure of autonomic modulation can be used in the establishment of CVT. More specifically, the log transformed high-frequency (HF) power of R-R intervals from electrocardiogram (ECG) measurements $\left(\operatorname{lnHF}_{\mathrm{R}-\mathrm{R}}\right)$ can be used to determine CVT. There is an association between reduced HRV and mortality [8] [9] [10] and HRV has been demonstrated to be significantly associated with the development of coronary heart disease in diabetics [11].

Since AIx and CVT are important determinants of cardiovascular health, it is important to comprehend the relationship between these measures, in an effort to elucidate the roles these determinants play in the cardiovascular health mosaic. This understanding could be significantly increased by gaining knowledge of how other factors, such as gender, cardiorespiratory fitness, age and ethnicity, affect this relationship. Gender is of particular importance as it has been shown to influence the development of coronary heart disease [12] and readmission to the hospital within the first year after myocardial infarction [13]. Cardiorespiratory fitness can be determined by maximum oxygen consumption $\left(\mathrm{VO}_{2} \mathrm{max}\right)$. Regarding cardiorespiratory fitness, increased cardiorespiratory fitness has been shown to have an inverse association with AIx in men [14] [15] and a positive impact on coronary heart disease [16] and heart failure [17]. However, there is need for further research to corroborate the association between cardiorespira- 
tory fitness and AIx.

Despite the increased knowledge to be gained from examining the relationship between AIx and CVT from a gender perspective, there is a paucity of research in this area. Such research could lead to clearer concepts of the pathophysiological involvement of AIx and CVT in cardiovascular disease.

Therefore, the purpose of this study was to examine the association between AIx@75 and CVT in men and women. Additionally, since cardiorespiratory fitness affects AIx and cardiovascular health, the secondary purpose of this study was to determine the association between cardiorespiratory fitness and AIx@75 in men and women. We hypothesized that the associations between CVT, cardiorespiratory fitness, and AIx@75 would differ based on gender.

\section{Methods}

\subsection{Subjects and Test Procedures}

The total sample recruited for the study included 82 participants from the Southern Connecticut State University student population. Two participants demonstrated ECG abnormality and were not included in the study. Eighty participants completed the study. Inclusion criteria included no history of smoking; having no clinical indications of cardiovascular, pulmonary, or metabolic disease; medication free and having normal ECG and blood pressure patterns. Descriptive indicators are listed in Table 1(a), and statistics

Table 1. (a) Descriptive characteristics based on gender; (b) Values of augmentation index at 75 beats $\mathrm{min}^{-1}$, heart rate variability and maximum oxygen consumption.

(a)

\begin{tabular}{ccccc}
\hline & Women $(\mathrm{n}=41)$ & Men $(\mathrm{n}=39)$ & $P^{\mathrm{a}}$ & Total $(\mathrm{n}=80)$ \\
\hline Age $($ years $)$ & $22.0 \pm 3.1$ & $22.3 \pm 3.5$ & 0.778 & $22.2 \pm 3.3$ \\
Height $(\mathrm{cm})$ & $164.8 \pm 6.7$ & $176.9 \pm 6.6$ & $<0.001^{\mathrm{e}}$ & $170.7 \pm 9.0$ \\
Body mass $(\mathrm{kg})$ & $64.2 \pm 10.9$ & $78.6 \pm 10.7$ & $<0.001^{\mathrm{e}}$ & $71.2 \pm 13.0$ \\
BMI $\left(\mathrm{kg} \cdot \mathrm{m}^{-2}\right)^{\mathrm{b}}$ & $23.6 \pm 3.7$ & $25.1 \pm 3.2$ & 0.061 & $24.3 \pm 3.5$ \\
SBP $(\mathrm{mmHg})^{\mathrm{c}}$ & $104 \pm 7.1$ & $111 \pm 7.3$ & $<0.001^{\mathrm{e}}$ & $107 \pm 8.0$ \\
DBP $(\mathrm{mmHg})^{\mathrm{d}}$ & $63 \pm 4.8$ & $67 \pm 7.2$ & $0.004^{\mathrm{e}}$ & $65 \pm 6.4$ \\
\hline
\end{tabular}

Data are mean \pm standard deviation; ${ }^{a} P$ values from an independent $\mathrm{t}$-test; ${ }^{\mathrm{b}}$ Body mass index; 'Systolic blood pressure; ${ }^{\mathrm{d}}$ Diastolic blood pressure; ${ }^{\mathrm{e}} P<0.005$.

(b)

\begin{tabular}{ccccc}
\hline & $\begin{array}{c}\text { Women } \\
(\mathrm{n}=41)\end{array}$ & $\begin{array}{c}\text { Men } \\
(\mathrm{n}=39)\end{array}$ & $P^{\mathrm{a}}$ & $\begin{array}{c}\text { Total } \\
(\mathrm{n}=80)\end{array}$ \\
\hline $\mathrm{AIx} 95(\%)^{\mathrm{b}}$ & $10.4 \pm 9.7$ & $0.4 \pm 11.4$ & $<0.001^{\mathrm{d}}$ & $5.5 \pm 11.6$ \\
$\operatorname{lnHF} \mathrm{R}_{\mathrm{R}}\left(\mathrm{ms}^{2}\right)^{\mathrm{c}}$ & $7.1 \pm 1.0$ & $7.2 \pm 1.0$ & 0.706 & $7.2 \pm 1.0$ \\
$\mathrm{VO}_{2} \mathrm{max}\left(\mathrm{mL} \cdot \mathrm{kg}^{-1} \cdot \mathrm{min}^{-1}\right)$ & $39.5 \pm 7.1$ & $50.9 \pm 7.2$ & $<0.001^{\mathrm{d}}$ & $45.1 \pm 9.1$ \\
\hline
\end{tabular}

Data are mean \pm standard deviation; ${ }^{a} P$ values from an independent t-test; ${ }^{\mathrm{b}}$ The augmentation index at a heart rate of 75 beats. $\mathrm{min}^{-1}$; ${ }^{\mathrm{C}}$ The high-frequency power of R-R intervals; ${ }^{\mathrm{d}} P<0.005$. 
for the variables of the log transformed HF power of R-R intervals from ECG measurements as $\operatorname{lnHF}_{\mathrm{R}-\mathrm{R}}$, used as an indicator of CVT; maximal oxygen consumption as $\mathrm{VO}_{2} \mathrm{max}$, used as an indicator of cardiorespiratory fitness along with AIx@75 are in Table 1(b). This study was approved by the Institutional Review Board at Southern Connecticut State University, and all participants gave informed consent.

Participants arrived for testing between 7:00 and 10:00 a.m. Prior to arrival they were advised not to exercise or consume food for 48 and 12 hours, respectively, prior to testing but were allowed to drink water. Women were tested within the first five days after menstruation to standardize and minimize the influence of hormonal levels on autonomic function [18]. The assessments were performed in a temperature controlled room with an ambient temperature of $21^{\circ} \mathrm{C}$. Anthropometric measurements were taken, and after 5 minutes of seated rest, two to three blood pressure measurements were taken; the mean value was used to indicate systolic blood pressure (SBP) and diastolic blood pressure (DBP).

\subsection{Assessment of AIx}

The SphygmoCor system (AtCor Medical Pty Ltd., West Ryde, Australia) used pulse wave analysis [19] to determine AIx. A high-fidelity transducer applanation tonometer was placed over the left radial pulse. The system then analyzed the radial waveform via the use of a generalized transfer function that was validated intra-arterially [20] [21] to determine AIx, which was established as the difference between the main outgoing wave and the reflected wave of the central waveform, expressed as a percent of the central pulse pressure. Since heart rate has an effect on pressure augmentation [3] [19], AIx values were adjusted to a standard heart rate of 75 beats·min ${ }^{-1}$, denoted AIx@75. Measurements were taken from the left radial pulse after 6 minutes of rest in a seated position. The SphygmoCor system automatically captured the data when the incorporated quality control component determined that the data were accurate. All collected data conformed to a research imposed $\geq 90 \%$ threshold of accuracy, determined by the system.

\subsection{Assessment of HRV}

Participants were then instrumented with a Nexfin monitor (BMEYE, Netherlands), which used ECG to determine continuous R-R interval measurements, which were taken for 8 minutes in a seated position at a sampling frequency of $1000 \mathrm{~Hz}$. Participants were asked to breathe at 12 breaths $\cdot \mathrm{min}^{-1}(0.2 \mathrm{~Hz})$ guided by a light moving up and down on a computer screen. This breathing protocol was implemented to avoid the effect of a varied respiratory rate on spectral distributions [22].

Power spectral density analysis of HRV via the fast Fourier transform was used to determine measures of HRV. A priori power spectra of R-R intervals 
within the $0.15-0.4 \mathrm{~Hz}$ range were defined as the HF component of HRV, of which vagal activity is a main contributor. The HF component is commonly used as an index of efferent vagal activity [23] and was used in this study as a measure of CVT. The absolute value of the HF component was log transformed to remove skewness and minimize the large standard deviation customarily present in these data and was indicated as $\operatorname{lnHF} \mathrm{R}_{\mathrm{R}-\mathrm{R}}$.

\subsection{Determination of $\mathrm{VO}_{2} \max$}

$\mathrm{VO}_{2}$ max was used as a measure of cardiorespiratory fitness; values were derived using a ParvoMedics TrueOne 2400 metabolic measuring system (ParvoMedics, Sandy, UT). $\mathrm{VO}_{2}$ max testing was performed on a computer-controlled, motorized Trackmaster Treadmill (Full Vision Inc., Newton, KS) using the Bruce Treadmill Protocol [24]. The fatigue level of participants was assessed via the Borg rating of perceived exertion scale; this assessment was taken at the end of each stage of the protocol. The stage progressed from the previous one every 3 minutes by increasing the work rate (speed and grade), until $\mathrm{VO}_{2} \max$ was reached. $\mathrm{VO}_{2} \max$ was confirmed in all subjects by obtaining a combination of at least two of the four following criteria: a plateau in oxygen consumption despite an increased work rate; a respiratory exchange ratio (RER) > 1.10; a heart rate within 10 beats. $\mathrm{min}^{-1}$ of the age-predicted maximum (220-age); or volitional fatigue. Data from any participants who did not meet two of these criteria were not retained for the analyses.

\section{Statistical Analysis}

Means and standard deviations are presented for the descriptive characteristics variables of age (years), height (centimeters), body mass (kilograms), body mass index $\left(\mathrm{kg} \cdot \mathrm{m}^{-2}\right)$, SBP (millimeter of mercury) and DBP (millimeter of mercury) for men and women and for the total sample. Statistics are also presented for AIx@75, lnHF $F_{R-R}$ and $\mathrm{VO}_{2}$ max. Independent sample t-tests were performed to determine if differences in the aforementioned variables exist by gender. Levene's test was also performed on each pair-wise comparison to test for homogeneity of variance, followed by a calculation for the Bonferroni correction. To assess the association between the predictor variables of $\operatorname{lnHF}_{\mathrm{R}-\mathrm{R}}, \mathrm{VO}_{2} \mathrm{max}$, and gender and the outcome variable AIx@75, multiple regression analyses were performed. Correlations were determined by Pearson correlation. Significance was set at $P<0.05$ for all statistics except those derived from the t-tests. Statistics and analyses were obtained using SPSS for Windows, Version 23 (IBM Corporation 2015, Armonk, NY).

\section{Results}

Only 80 of the 82 participants completed the study protocol (41 women, 39 men). Table 1(a) shows the sample descriptive statistics (mean \pm standard deviation) for the participants in this study, by gender and combined. Table 1(b) 
shows the sample statistics for the variables of AIx@75, lnHF $\mathrm{R}_{\mathrm{R}-\mathrm{R}}$, and $\mathrm{VO}_{2} \max$, by gender and combined. Independent sample t-tests indicated significant differences in the means between men and women for the descriptive variables of height, with men having greater height $(P<0.001)$ and greater body mass $(P<$ $0.001)$; SBP and DBP were also significantly higher in men $(P<0.001)$ and $(P<$ 0.004 , respectively; Table $1(\mathrm{a}))$ versus women. Gender differences were also found for $\mathrm{VO}_{2} \max$, with men having greater $\mathrm{VO}_{2} \max (P<0.001)$ and women having greater AIx@75 $(P<0.001$; Table $1(\mathrm{~b}))$. The $P$ values for all the significant differences were less than the family-wise Bonferroni corrected $P$ value of 0.005 .

Table 2 shows significant correlations between AIx@75, $\operatorname{lnHF}_{\mathrm{R}-\mathrm{R}}$, and $\mathrm{VO}_{2} \max$ in men but not women. A stepwise multiple linear regression was performed with AIx@75 as the outcome and $\operatorname{lnHF}_{\mathrm{R}-\mathrm{R}}, \mathrm{VO}_{2} \max$, and gender (dummy variable) as the predictors. Table 3 shows the model summary for this analysis. Here it was demonstrated that the variable entered at each stage of the model's development accounted for a significant increase in the overall robustness of the model, which accounted for $29.6 \%$ of the variation in AIx@75. In this model $\mathrm{VO}_{2} \max$ accounts for $19.7 \%$ of the variation in AIx@75, while $\operatorname{lnHF}_{\mathrm{R}-\mathrm{R}}$ and gender account for 6.1 and $3.8 \%$, respectively. Table 4 shows that when the main

Table 2. Pearson correlations $\left(r\right.$ ) between $\operatorname{lnHF}_{\mathrm{R}-\mathrm{R}}$ and AIx@75, and between $\mathrm{VO}_{2} \max$ and AIx@75 in men $(\mathrm{n}=39)$ and women $(\mathrm{n}=41)$.

\begin{tabular}{ccc}
\hline & $\operatorname{lnHF}_{\mathrm{R}-\mathrm{R}}\left(\mathrm{ms}^{2}\right)$ & $\mathrm{VO}_{2} \max \left(\mathrm{mL} \cdot \mathrm{kg}^{-1} \cdot \mathrm{min}^{-1}\right)$ \\
\hline $\mathrm{AIx}$ @75 (\%) & & \\
Men & $0.38(0.02)^{\mathrm{a}}$ & $-0.33(0.04)^{\mathrm{a}}$ \\
Women & $0.10(0.52)$ & $-0.16(0.32)$ \\
\hline
\end{tabular}

${ }^{\text {a }} P<0.05$

Table 3. Model summary for the stepwise linear regression with AIx@75 as outcome.

\begin{tabular}{|c|c|c|c|c|c|c|}
\hline \multirow{2}{*}{ Model } & \multirow{2}{*}{$\begin{array}{l}\text { Variable } \\
\text { Entered }\end{array}$} & \multirow{2}{*}{$\mathbf{R}$} & \multirow{2}{*}{$\mathbf{R}^{2}$} & \multicolumn{3}{|c|}{ Change Statistics } \\
\hline & & & & $\mathrm{R}^{2}$ Change & F Change & Sig. F Change \\
\hline 1 & $\mathrm{VO}_{2} \max$ & 0.444 & 0.197 & 0.197 & 19.193 & $<0.001^{\mathrm{a}}$ \\
\hline 2 & $\ln H F_{\mathrm{R}-\mathrm{R}}$ & 0.508 & 0.258 & 0.061 & 6.325 & $0.014^{\mathrm{a}}$ \\
\hline 3 & Gender & 0.544 & 0.296 & 0.038 & 4.059 & $0.047^{\mathrm{a}}$ \\
\hline
\end{tabular}

${ }^{\mathrm{a}} P<0.05$.

Table 4. Model summary of linear regression by gender with AIx@75 as outcome.

\begin{tabular}{cccccc}
\hline \multirow{2}{*}{ Gender } & \multirow{2}{*}{$\mathbf{R}$} & $\mathbf{R}^{2}$ & \multicolumn{3}{c}{ Change Statistics } \\
\cline { 4 - 6 } & & & $\mathrm{R}^{2}$ Change & F Change & Sig. F Change \\
\hline Women & $0.192^{\mathrm{a}}$ & 0.037 & 0.037 & 0.730 & 0.488 \\
Men & $0.535^{\mathrm{b}}$ & 0.287 & 0.287 & 7.229 & $0.002^{\mathrm{a}}$ \\
\hline
\end{tabular}

${ }^{\mathrm{a}} P<0.05$. 
group was divided by gender with AIx@75 as the outcome variable and $\operatorname{lnHF}_{\mathrm{R}-\mathrm{R}}$ and $\mathrm{VO}_{2}$ max as predictors, only the model for men was found to be significant. Table 5 shows that the variables of $\mathrm{VO}_{2} \max$ and $\operatorname{lnHF}_{\mathrm{R}-\mathrm{R}}$ account for an approximately equal percentage of the variation in AIx@75. Table 6 shows the results of a linear regression analysis with AIx@75 as the outcome and $\mathrm{VO}_{2} \max$ and $\operatorname{lnHF}_{\mathrm{R}-\mathrm{R}}$ as predictors, for men and women. For women, no predictor was significant, indicating that AIx@75 was not a function of $\mathrm{VO}_{2} \max$ or $\operatorname{lnHF}_{\mathrm{R}-\mathrm{R}}$ for women. Table 6 shows that for men the variables of $\mathrm{VO}_{2} \max$ and $\operatorname{lnHF} \mathrm{R}_{\mathrm{R} R}$ were significant predictors of AIx@75, accounting for approximately $28.7 \%$ of the variation in AIx@75.

\section{Discussion}

The main finding of this study was that the associations between $\operatorname{lnHF}_{\mathrm{R}-\mathrm{R}}$ and AIx@75 and between $\mathrm{VO}_{2} \max$ and AIx@75 were not the same in men and women. Additionally, $\mathrm{VO}_{2} \max$ was found to be a more robust indicator of AIx@75 versus $\operatorname{lnHF}_{\mathrm{R}-\mathrm{R}}$ in a combined group of men and women, while in the men's group, $\mathrm{VO}_{2} \max$ and $\operatorname{lnHF}_{\mathrm{R}-\mathrm{R}}$ accounted for approximately the same amount of variation in AIx@75.

In the current study, $\operatorname{lnHF}_{\mathrm{R}-\mathrm{R}}$ and $\mathrm{VO}_{2}$ max were correlated and were significant predictors of AIx@75 in men but not women. In men there was a positive correlation between $\operatorname{lnHF_{R-R}}$ and AIx@75; for every unit increase in $\operatorname{lnHF}_{\mathrm{R}-\mathrm{R}}$ there was a 4.6 unit increase AIx@75. This finding was particularly interesting since increased sympathetic tone has been found to be associated with increased AIx in men [25], while parasympathetic tone is considered to impose tonic restrain

Table 5. Model summary for the stepwise linear regression with AIx@75 as outcome.

\begin{tabular}{ccccccc}
\hline \multirow{2}{*}{ Gender } & \multirow{2}{*}{ Model } & & & \multirow{2}{*}{$\mathbf{R}^{2}$} & \multicolumn{3}{c}{ Change Statistics } \\
\cline { 5 - 7 } & & & & $\mathrm{R}^{2}$ Change & F Change & Sig. F Change \\
\hline \multirow{2}{*}{ Men } & $\mathrm{VO}_{2} \max$ & 0.375 & 0.141 & 0.141 & 6.072 & $0.019^{\mathrm{a}}$ \\
& $\operatorname{lnHF}_{\mathrm{R}-\mathrm{R}}$ & 0.535 & 0.287 & 0.146 & 7.345 & $0.010^{\mathrm{a}}$ \\
\hline
\end{tabular}

${ }^{\mathrm{a}} P<0.05$.

Table 6. Model coefficients.

\begin{tabular}{ccccccc}
\hline \multirow{2}{*}{ Model } & \multicolumn{2}{c}{$\begin{array}{c}\text { Unstandardized } \\
\text { Coefficients }\end{array}$} & $\begin{array}{c}\text { Standardized } \\
\text { Coefficients }\end{array}$ & \multirow{2}{*}{$\mathbf{t}$} & \multirow{2}{*}{ Sig. } \\
\cline { 3 - 5 } & & $\mathrm{B}$ & Std. Error & Beta & & \\
\hline \multirow{3}{*}{ Women } & $($ Constant $)$ & 11.825 & 13.693 & & 0.864 & 0.393 \\
& $\operatorname{lnHF}_{\mathrm{R}-\mathrm{R}}$ & 1.034 & 1.504 & 0.109 & 0.687 & 0.496 \\
& $\mathrm{VO}_{2} \mathrm{max}$ & -0.221 & 0.218 & -0.162 & -1.016 & 0.316 \\
& $($ Constant $)$ & -2.360 & 14.919 & & -0.158 & 0.875 \\
\multirow{3}{*}{ Men } & $\operatorname{lnHF}_{\mathrm{R}-\mathrm{R}}$ & 4.640 & 1.537 & 0.429 & 3.018 & $0.005^{\mathrm{a}}$ \\
& $\mathrm{VO}_{2} \mathrm{max}$ & -0.607 & 0.224 & -0.385 & -2.710 & $0.014^{\mathrm{a}}$ \\
\hline
\end{tabular}

${ }^{\mathrm{a}} P<0.05$. 
on sympathetic tone. Because of this tonic restrain or the somewhat opposite nature of parasympathetic and sympathetic tone, one could speculate that increased $\ln \mathrm{HF}_{\mathrm{R}-\mathrm{R}}$ should be associated with an attenuation in AIx@75; however, this study did not support this assumption. The positive association between $\operatorname{lnHF}_{\mathrm{R}-\mathrm{R}}$ and AIx@75 suggests that both parasympathetic and sympathetic tone could have a positive association with AIx@75. However, the mechanisms through which these branches of the autonomic nervous system act to increase AIx@75 might be different. The concept of a positive association between $\operatorname{lnHF}_{\mathrm{R}-\mathrm{R}}$ and $\mathrm{AIx}$ is plausible, since $\operatorname{lnHF}_{\mathrm{R}-\mathrm{R}}$ could result in the slowing of the heart rate [26]. This slowing of the heart could result in a greater ventricular ejection period of the cardiac cycle, which could lead to summation of both the incident and reflected wave [19] and thus increase AIx. Though this could be an explanation of how $\operatorname{lnHF}_{\mathrm{R}-\mathrm{R}}$ could increase $\mathrm{AIx}$, in the current study, heart rate was controlled at 75 beats. $\mathrm{min}^{-1}$; therefore, reduced heart rate was not a contributing factor. Since both increased $\operatorname{lnHF}_{\mathrm{R}-\mathrm{R}}$ and reduced AIx@75 are considered to be positive indicators of cardiovascular health, their positive association was not expected and underscores the need for further research examining this association.

$\mathrm{VO}_{2} \max$ was inversely correlated with and was a significant predictor of AIx@75 in men but not women; for every unit increase in $\mathrm{VO}_{2} \max , \mathrm{AIx}$ (75 decreased by 0.60 unit, suggesting that cardiorespiratory fitness is very important in reducing AIx@75 in men. The stepwise multiple linear regression model demonstrated that in the combined group of men and women, $\mathrm{VO}_{2} \max$ accounted for $19.7 \%$ of the variation in AIx@75, with $\operatorname{lnHF}_{\mathrm{R}-\mathrm{R}}$ and gender accounting for 6.1 and $3.8 \%$, respectively. In the combined group, $\mathrm{VO}_{2}$ max was the most significant predictor of AIx@75 in the model, but when this association was examined in men, $\mathrm{VO}_{2}$ max and $\ln \mathrm{HF}_{\mathrm{R}-\mathrm{R}}$ accounted for approximately equal portions of the variation in AIx@75, as observed when the change in $\mathrm{R}^{2}$ was approximately $14 \%$ for each predictor. Therefore, $\mathrm{VO}_{2} \mathrm{max}$ explained more of the variation in AIx@75 in the combined group of men and women.

Women demonstrated a significantly higher mean AIx@75 versus men, which corroborated with prior work [27]. This greater AIx@75 can be explained in part by women being significantly shorter than men, therefore having smaller aortas, giving rise to reflection sites that are closer to the heart and therefore earlier wave reflections [28]. Although our finding of women having significantly higher mean AIx@75 values than men corroborated with the findings of one prior study [25], women in the current study had a mean AIx@75 value that was greater than the value observed in the prior study. One possible explanation is that there could have been a difference in the phase of the menstrual cycle during which AIx@75 was measured in the current study versus the prior study. The phase of the menstrual cycle during which measures of arterial stiffness are taken is very important as arterial stiffness (of which AIx is an indicator) has been shown to differ during different phases of the menstrual cycle [29]. 
There was no significant mean difference in $\operatorname{lnHF}_{\mathrm{R}-\mathrm{R}}$ between men and women, although it has also been suggested that women have higher HRV versus men [30].

\section{Conclusion}

The association between AIx@75, CVT, and cardiorespiratory fitness is not the same in men and women. In men, as CVT increased, so did AIx@75, and increased cardiorespiratory fitness was associated with reduced AIx@75; these associations were not observed in women. Additionally, in a combined group of men and women, cardiorespiratory fitness was a more robust predictor of AIx@75 versus CVT. Findings from the present study suggest that the association between pertinent cardiovascular health indices differ by gender. Additionally, these findings underscore the need to consider factors that could influence the relationship between known indicators of cardiovascular health when assessing the efficacy of protocols geared toward improving cardiovascular health. While findings from the present study are intriguing, more research is needed in this area using larger sample size and different ethnic groups.

\section{References}

[1] Weber, T., Auer, J., O’Rourke, M.F., Kvas, E., Lassnig, E., Berent, R. and Eber, B. (2004) Arterial Stiffness, Wave Reflections, and the Risk of Coronary Artery Disease. Circulation, 109, 184-189. https://doi.org/10.1161/01.CIR.0000105767.94169.E3

[2] Elik, G., Demirci, M., Tumuklu, M., Asci, G., Sipahi, S., Toz, H., Basci, A. and Ok, E. (2011) Factors Related to Pulse Wave Velocity and Augmentation Index in Chronic Hemodialysis Patients. Renal Failure, 33, 957-963. https://doi.org/10.3109/0886022X.2011.615967

[3] Wilkinson, I., MacCallum, H., Flint, L., Cockcroft, J., Newby, D. and Webb, D. (2000) The Influence of Heart Rate on Augmentation Index and Central Arterial Pressure in Humans. The Journal of Physiology, 525, 263-270. https://doi.org/10.1111/j.1469-7793.2000.t01-1-00263.x

[4] Mattace-Raso, F.U.S., van der Cammen, T.J.M., Hofman, A., van Popele, N., Bos, M.L., Schalekamp, M.A.D.H., Asmar, R., Reneman, R.S., Hoeks, A.P.G., Breteler, M.M.B. and Witteman, J.C.M. (2006) Arterial Stiffness and Risk of Coronary Heart Disease and Stroke. Circulation, 113, 657-663. https://doi.org/10.1161/CIRCULATIONAHA.105.555235

[5] Cruickshank, K., Riste, L., Anderson, S.G., Wright, J.S., Dunn, G. and Gosling, R.G. (2002) Aortic Pulse-Wave Velocity and Its Relationship to Mortality in Diabetes and Glucose Intolerance: An Integrated Index of Vascular Function? Circulation, 106, 2085-2090. https://doi.org/10.1161/01.CIR.0000033824.02722.F7

[6] Nurnberger, J., Keflioglu-Scheiber, A., Opazo Saez, A.M., Wenzel, R.R., Philipp, T. and Schafers, R.F. (2002) Augmentation Index Is Associated with Cardiovascular Risk. Journal of Hypertension, 20, 2407-2414. https://doi.org/10.1097/00004872-200212000-00020

[7] London, G.M., Blacher, J., Pannier, B., Guerin, A.P., Marchais, S.J. and Safar, M.E. (2001) Arterial Wave Reflections and Survival in End-Stage Renal Failure. Hyper- 
tension, 38, 434-438. https://doi.org/10.1161/01.HYP.38.3.434

[8] Thayer, J.F. and Sandhya, R.D. (2007) The Role of Vagal Function in the Risk for Cardiovascular Disease and Mortality. Biological Psychology, 74, 224-242.

[9] La Rovere, M.T., Bigger, J.T., Marcus, F.L., Mortara, A. and Schwartz, P.J. (1998) Baroreflex Sensitivity and Heart Rate Variability in Prediction of Total Cardiac Mortality after Myocardial Infarction. ATRAMI (Autonomic Tone and Reflexes after Myocardial Infarction Investigators). The Lancet, 351, 478-484.

[10] Kleiger, R.E., Miller, J.P., Bigger, J.T. and Moss, A.J. (1987) Decreased Heart-Rate Variability and Its Association with Increased Mortality after Acute Myocardial-Infarction. American Journal of Cardiology, 59, 256-262.

[11] Liao, D., Carnethon, M., Evans, G.W., Cascio, W.E. and Heiss, G. (2002) Lower Heart Rate Variability Is Associated with the Development of Coronary Heart Disease in Individuals with Diabetes-The Atherosclerosis Risk in Communities (Aric) Study. Diabetes, 51, 3524-3531. https://doi.org/10.2337/diabetes.51.12.3524

[12] Maas, A.H.E.M. and Appleman, Y.E.A. (2010) Gender Differences in Coronary Heart Disease. Netherlands Heart Journal, 18, 598-602. https://doi.org/10.1007/s12471-010-0841-y

[13] Lundback, M., Gasevic, D., Rullman, E., Ruge, T., Carlsson, A.C. and Holzmann, M.J. (2017) Sex-Specific Risk of Emergency Department Revisit and Early Readmission Following Myocardial Infarction. International Journal of Cardiology, S0167-5273, 30170-30175.

[14] Denham, J., Brown, N.J., Tomaszewski, M., William, B., O’Brien, B.J. and Charchar, F.J. (2016) Aortic Augmentation Index in Endurance Athletes: A Role for Cardiorespiratory Fitness. European Journal of Applied Physiology, 116, 1537-1544. https://doi.org/10.1007/s00421-016-3407-x

[15] Binder, J., Bailey, K.R., Seward, J.B., Squires, R.W., Kunihiro, T., Hensrud, D.D. and Kullo, I.J. (2006) Aortic Augmentation Index Is Inversely Associated with Cardiorespiratory Fitness in Men without Known Coronary Heart Disease. The American Journal of Hypertension, 19, 1019-1024.

[16] Jette, M., Sidney, K., Quenneville, J. and Landry, F. (1992) Relationship between Cardiorespiratory Fitness and Selected Risk Factors for Coronary Heart Disease in a Population of Men and Women. Canadian Medical Association Journal, 146, 1353-1360.

[17] Khan, H., Kunutsor, S., Rauramaa, R., Savonen, K., Kalogeropoulos, A.P., Georgiopoulou V.V., Butler, J. and Laukkanen, J.A. (2014) Cardiorespiratory Fitness and Risk of Heart Failure: A Population-Based Follow-Up Study. European Journal of Heart Failure, 16, 180-188. https://doi.org/10.1111/ejhf.37

[18] Leicht, A.S., Hirning, D.A. and Allen, G.D. (2002) Heart Rate Variability and Endogenous Sex Hormones during the Menstrual Cycle in Young Women. Experimental Physiology, 88, 441-446. https://doi.org/10.1113/eph8802535

[19] O’Rourke, M.F., Pauca, A.L. and Jiang, X. (2001) Pulse Wave Analysis. The Journal of Clinical Pharmacology, 51, 507-522.

https://doi.org/10.1046/j.0306-5251.2001.01400.x

[20] Pauca, A.L., O’Rourke, M.F. and Kon, N.D. (2001) Prospective Evaluation of a Method for Estimating Ascending Aortic Pressure from the Radial Artery Pressure Waveform. Hypertension, 38, 932-937. https://doi.org/10.1161/hy1001.096106

[21] Chen, C.H., Nevo, E., Fetics, B., Pak, P.H., Yin, F.C., Maughan, W.L. and Kass, D.A. (1997) Estimation of Central Aortic Pressure Waveform by Mathematical Transformation of Radial Tonometry Pressure. Validation of Generalized Transfer Func- 
tion. Circulation, 95, 1827-1836. https://doi.org/10.1161/01.CIR.95.7.1827

[22] De Meersman, R., Reisman, S., Daum, M., Zorowitz, R. and Findley, T. (1995) Influence of Respiration on Metabolic, Hemodynamic, Psychometric, and R-R Interval Spectral Parameters. American Journal of Physiology. Heart and Circulatory Physiology, 269, H1437-H1544.

[23] Task Force of the European Society of Cardiology and the North American Society of Pacing and Electrophysiology (1996) Heart Rate Variability. Standards of Measurement, Physiological Interpretation, and Clinical Use. Circulation, 93, 1043-1065. https://doi.org/10.1161/01.CIR.93.5.1043

[24] Bruce, R.A., Blackmon, J.R., Jones, J.W. and Strait, G. (1963) Exercise Testing in Adult Normal Subjects and Cardiac Patients. Pediatrics, 32, 742-756.

[25] Casey, D.P., Curry, T.B., Joyner, M.J., Charkoudian, N. and Hart, E.C. (2011) Relationship between Muscle Sympathetic Nerve Activity and Aortic Wave Reflection Characteristics in Young Men and Women. Hypertension, 57, 421-427. https://doi.org/10.1161/HYPERTENSIONAHA.110.164517

[26] Olshansky, B., Sabbah, H.N., Hauptman, P.J. and Colucci, W.S. (2008) Parasympathetic Nervous System and Heart Failure: Pathophysiology and Potential Implications for Therapy. Circulation, 118, 863-871. https://doi.org/10.1161/CIRCULATIONAHA.107.760405

[27] Kim, J.Y., Park, J.B., Kim, D.S., Kim, K.S., Jeong, J.W., Park, J.C., Oh, B.H. and Chung, N. (2014) Gender Difference in Arterial Stiffness in a Multicenter Cross-Sectional Study: The Korean Arterial Ageing Study. Pulse, 2, 11-17. https://doi.org/10.1159/000365267

[28] Smulyan, H., Marchais, S.J., Pannier, B., Guerin, A.P., Safar, M.E. and London, G.M. (1998) Influence of Body Height on Pulsatile Arterial Hemodynamic Data. Journal of the American College of Cardiology, 31, 1103-1109.

[29] Madhura, M. and Sandhya, T.A. (2014) Effect of Different Phases of Menstrual Cycle on Reflection Index, Stiffness Index, and Pulse Wave Velocity in Healthy Subjects. Journal of Clinical and Diagnostic Research, 8, BC01-BC04.

[30] Gregoire, J., Tuck, S., Yamamoto, Y. and Hughson, R.L. (1996) Heart Rate Variability at Rest and Exercise: Influence of Age, Gender, and Physical Training. Canadian Journal of Applied Physiology, 22, 455-470. https://doi.org/10.1139/h96-040

\section{Submit or recommend next manuscript to SCIRP and we will provide best service for you:}

Accepting pre-submission inquiries through Email, Facebook, LinkedIn, Twitter, etc. A wide selection of journals (inclusive of 9 subjects, more than 200 journals) Providing 24-hour high-quality service User-friendly online submission system Fair and swift peer-review system Efficient typesetting and proofreading procedure Display of the result of downloads and visits, as well as the number of cited articles Maximum dissemination of your research work

Submit your manuscript at: http://papersubmission.scirp.org/ Or contact ojmip@scirp.org 